Journal of Tropical Resources and Sustainable Science

journal homepage: jtrss.org

\title{
Comparative study of hatchability rate and egg quality between different strains of Japanese Quail (Coturnix japonica)
}

\author{
Muhammad Amiruddin Wahab ${ }^{1}$, Khairiyah Mat ${ }^{1,2, *}$, Mohamad Faiz Mohd Nor ${ }^{1}$, Muhammad Aiman Adam ${ }^{1}$, \\ Muhammad Syazwan Ramli ${ }^{1}$, Nor Dini Rusli ${ }^{1,2}$, Che Harun Hasnita ${ }^{1,2}$, Raja Ili Airina Raja Khalif ${ }^{1}$ \\ ${ }^{1}$ Faculty of Agro Based Industry, Universiti Malaysia Kelantan, Kelantan, Malaysia. \\ ${ }^{2}$ Institute of Food Security and Sustainable Agriculture, Universiti Malaysia Kelantan Jeli Campus, Locked Bag 100, 17600 Jeli, \\ Kelantan, Malaysia.
}

Received 24 September 2017

Accepted 8 October 2017

Online 13 December 2018

Keywords:

Japanese quail, strain, morphology, hatchability rate, egg quality

$\bigotimes *$ Corresponding author: Dr. Khairiyah Mat

Faculty of Agro Based

Industry, Universiti Malaysia

Kelantan, Kelantan, Malaysia.

Tel: +609-9477000, Fax: +6099477022,

Email:khairiyah@umk.edu.my

\begin{abstract}
The objectives of this study were to determine morphology of Japanese quail strains and hatchability rate and egg quality between commercial strain which is Poultry Progress Institute (IKTA) strain and White Texas strains of Japanese Quail (Coturnix japonica) rear in Malaysia. A total of 300 quails were randomly picked and the breastbone length, chest girth, body weight, body length, shank length and drum length were measured for the morphology. Then, 270 eggs of Commercial and White Texas strains were used to test the hatchability rate $(n=150)$ and egg quality $(n=120)$. The ratio of the parents of the quails between male and female of each type of strain were 1:3. The cleanliness, shape, weight, and texture of the eggshell were observed, weighed and measured. The eggs were incubated for 17 days $\left(37.6{ }^{\circ} \mathrm{C}, 65 \%\right.$ humidity). The shape index, egg weight, egg volume and eggshell surface were weighed and measured for the exterior trait of eggs. For interior trait, the albumen index, Haugh units, and internal quality units (IQU) were measured. Significant findings were observed in all of the features $(\mathrm{P}<0.05)$, except for the wing length in morphology. For hatchability rate, there was a high significant in the percentage of hatchability of incubated eggs, hatchability of fertile eggs and smoothness texture of the eggshell. In egg quality there was high significant in Haugh unit but low significant internal quality unit. The significant variability might be due from the genetic information that inherited from the parents. The IKTA and White strains were not the same in morphology, hatchability rate and interior trait of eggs but same exterior trait of eggs. In conclusion, this research is important in giving information about Japanese quail strain in Malaysia and more genetic study should be done in the future to determine good strain and increase understanding about quail strain.
\end{abstract}

() 2018 UMK Publisher. All rights reserved.

\section{INTRODUCTION}

Japanese quail is one type of the bird species in this world that are categorised to the order Galiformes, genus Coturnix, and species japonica. The scientific designation for Japanese quail is Coturnix japonica, which is varies from the common quail (Coturnix coturnix) (Vali, 2008). Japanese quail can be found easily in many countries as migrating birds (Mizutani, 2003). In the Japanese quail, there are a few different types of strain that had been formed because the genetic information carried by them which that they had been inherited it from their parents.

Quail egg is usually smaller in size compare to other poultry animals like duck and chicken (Hauber, 20014). The normal weight of the quail egg is around 1012 grams each (Hrncar, Hasunova, Hanus and Bujko, 2014). The average weight of quail yolk is around 4.3-4.5 grams where the weight of yolk largely determined the nutritional value of the egg, average weight of albumen of quail eggs is around 4.9-5.0 grams which is about 53.5$59.5 \%$ of the total egg weight and the thickness of quail eggs with membranes differ from range 0.191 to 0.219 mm (Genchev, 2012a).

Hatchability rate is a function of number of chicks hatched, and it is affected by various factors. The main factor that influenced hatchability and weight of the day-old chick are fertility and egg quality (Alkan, Karabag, Galic and Balcioglu, 2008). According to previous study, the factor of age of quails can influences the quail egg weight which can affect the quality and production characteristics of the quail eggs that have relation with the hatchability rate of the quail (Zita, Ledvinka and Klesalova, 2013). Besides that, other factors that can disturb the success of the quality of hatched quail chicks or incubation are the turning process and egg position during the artificial incubation (Moraes, 
Romao, Teixeira and Cardoso, 2008). A study suggested that the egg geometry, egg quality and hatchability were varied from each other in different type of strains of the Japanese quail (Akram et al., 2014).

Egg quality traits had given a great significance in poultry breeding due to their influence on production and breeding performance, quality, and growth of the chicks. The specification during the selection or some traits of strains could show in lower values of other traits and that is why selection programmes was important as it can help in create strain specialised for specific traits (Lalev, 2013). The genetic potential occurred for egg production that was very high in two strains from the Japanese quail which is in the comparison between Pharaoh strain and Manchurian Gold strain with mean egg production intensity percentage around $80.5 \%$ and $75.8 \%$ in respectively with the significant value $(\mathrm{P}<0.001)$ (Genchev, 2012b).

Factors that influenced the quality of an egg which are breed, strain, variety, body weight, temperature, relative humidity, rearing practices and seasons (Jatoi et al., 2015). In contrast, previous research explained that the definitions of egg quality are those characteristics of an egg that affects its acceptability to consumers was composed (Hrncar, Hasunova, Hanus and Bujko, 2014). Hence, there are some requirements that need attention as for consumer's acceptability of shell eggs, the important quality characteristics can be relate to all of the external factors including cleanliness, freshness, egg weight, shell weight and on the acceptability of the consumers to buy the eggs.

A research had been carried out on the egg quality between different strain in Japanese quail manage to show that the Brown Japanese quails strain exhibited significantly higher means for egg width $(27.07 \mathrm{~mm})$, shell weight $(1.18 \mathrm{~g})$, albumen length $(44.03 \mathrm{~mm})$, yolk diameter $(25.30 \mathrm{~mm})$, yolk colour (5.50), shape index (79.57) and percentage of shell (8.61), while Black quails strain were found superior for albumen width $(33.98 \mathrm{~mm})$, albumen height $(4.98 \mathrm{~mm})$, albumen index (0.13) and Haugh unit score (59.50), it is proved that the existence of significant genetic differences in different type of strain of Japanese Quail (Kumari, Gupta, Prakash and Reddy, 2008).

In late 1990s, the Malaysia government agencies under Poultry Progress Institute (IKTA) had developed a new strain from the Japanese quail (Coturnix japonica) breed to help the quail farmers in Malaysia to produce the good quail strain in order to commercialize the quail as one of poultry industry segmentation. However, there was no basic information about the capability of this new strain of quail compare to other existing strain of Japanese quail (Coturnix japonica). Overall, the variation of results of egg quail in each different types of quail strain of Japanese quail is determined by the genetic information that had been transferred from the parents. It is important to do this study to improve the performance of egg production because nowadays, the cost of quail egg production right now had increase. This problem had caused the price of quail eggs arise as the demand for the quail eggs are increasing. If the genetics the quails can be improved for eggs production, it can help to produce more economically quail eggs besides can cater higher demand from consumers. This study is comparing the hatchability and egg quality performance between IKTA and White Texas strain of Japanese Quail to determine which is the best and economical value breed.

\section{MATERIALS AND METHODS}

\subsection{Data collection}

Two hundred and seventy eggs of IKTA and White Texas strain were used in this study. The eggs were collected from the Double Gold Farm Quail Farm, Ayer Lanas. The ratio of the parents of the quails between male and female of each type of strain were 1:3 and the ages of the quails were 65 days. One hundred and fifty sample of eggs from each strain were used for conducted the hatchability rate study and 120 sample of eggs were used for egg quality study. One hundred and fifty samples of eggs were divided into five replications that consists 15 eggs on each of replication of each strain. One hundred and twenty samples of eggs were divided into three replications that consists 20 eggs on each replication of each strain.

\subsection{Hatchability rate data recording}

One hundred and fifty eggs were collected from the Double Gold Farm Quail Farm, Ayer Lanas, Kelantan. The ratio of the parents of the quails between male and female of each type of strain were 1:3 and the ages of the quails were 65 days. The cleanliness, shape, weight, and texture of the eggshell were observed, weighed and measured. The collected eggs were separated according to the type of the strain. The eggs were incubated for 17 days at a temperature of $37.6{ }^{\circ} \mathrm{C}$ and a relative humidity of $65 \%$. During incubation the eggs were turned automatically every hour. At the end of the incubation period, the numbers of hatched quail chicks were counted and all dead embryo eggs were checked. All the data measurement of the hatchability rate was measured according to the type of strains and calculated according to Alkan, Karabag, Galic and Balcioglu, (2008) calculations (Eq 1-3).

(\%) Fertility $=$ (number of fertilized eggs/ total number of eggs placed into incubator) $\mathrm{x} 100$

(\%) Hatchability of incubated eggs = (number of released chicks/total number of eggs placed incubator) x 100

(\%)Hatchability of fertile eggs $=$ (number of released chicks/number of fertilized eggs placed in incubator) x 100.(3) 


\subsection{Egg quality data record}

One hundred and twenty eggs were collected from the Double Gold Farm Quail Farm, Ayer Lanas, Kelantan. The ratio of the parents of the quails between male and female of each type of strain were 1:3 and the ages of the quails were 65 days. The egg quality study was divided into exterior trait of eggs and interior trait of eggs. The shape index, egg weight, egg volume and eggshell surface were observed, weighed and measured for the exterior trait of eggs. The albumen index, Haugh units, and internal quality units (IQU) were observed and measured for the interior trait of eggs. The diameters of egg albumen and yolk were determined after breaking the egg on a horizontal smooth surface. The data for the egg quality were collected and analysed (Genchev, 2012a) and according to the equation for each parameter (Eq. 4-9):

Exterior trait of egg: Shape index (SI, \%) equation: $S I=d / D * 100$

Where, $d=$ the short axis of the egg, $D=$ the long axis of the egg.

Egg volume $\left(\mathrm{cm}^{3}\right)$ equation: $\mathrm{EV}=4 / 3 * \pi *(\mathrm{D} / 2) *(\mathrm{~d} / 2) 2$

Where, $d=$ the short axis of the egg, $D=$ the long axis of the egg, and $\pi=3.14159$.

Eggshell surface equation: $\mathrm{SSA}=4.835 * \mathrm{EW} 0.662$

Where $\mathrm{EW}=$ the egg weight.

Interior trait of egg: Albumen index equation:

$\mathrm{AI}=\mathrm{h} /\left(\left(0.5^{*}(\mathrm{D}+\mathrm{d})\right)\right.$

Where $\mathrm{h}=$ the height of thick albumen at the boundary with the yolk, $d=$ the short diameters of albumen measured on the smooth surface, $\mathrm{D}=$ the long diameters of albumen measured on the smooth surface.

Haugh units equation - Haugh (1937) : HU $=100 * \log (\mathrm{h}+7.57-$ $1.7 *$ EW0.37)

Where, $\mathrm{h}=$ the height of thick albumen at the boundary with the yolk, $\mathrm{EW}=$ the egg weight.

Internal quality units equation - Haugh (1937): IQU= $100 * \log (\mathrm{h}+4.18-0.89897 *$ EW0.6674)

Where, $\mathrm{h}=$ the height of thick albumen at the boundary with the yolk, EW= the egg weight.

\subsection{Statistical analysis}

The mean, standard deviation (SD) and standard error of mean (SEM) were find and then the results were analysed by using IBM SPSS Statistics 23 for in the hatchability rate (shape index, cleanliness, eggshell texture, and egg weight), in the egg quality in exterior part (shape index, egg volume, egg weight and eggshell surface) and interior part (albumen index, Haugh units, and internal quality units). The statements of statistical significant were based on $(\mathrm{P}<0.05)$.

\section{RESULTS AND DISCUSSION}

Hatchability rate and egg quality between Commercial and White Texas strain were being compared to determine which strain is the best in hatchability and egg quality. For hatchability rate, in Table 1 showed the Percentage of hatchability rate between each strain. The parameters measured were hatchability of incubated eggs, fertility and hatchability of fertile eggs. In Table 2 showed the Parameter of hatchability rate between each strain. The parameters measured were cleanliness of the eggs, smoothness texture of the eggshell, weight of the eggs and shape index. The results were highly significant $(\mathrm{P}<0.05)$ in percentage of hatchability of incubated egg, percentage of hatchability of fertile eggs, and smoothness texture of the eggshell.

Table 1: The percentage of hatchability rate between each strain

\begin{tabular}{lccc}
\hline Breed & $\begin{array}{l}\text { Hatchability } \\
\text { of Incubated } \\
\text { Eggs }(\%)\end{array}$ & $\begin{array}{l}\text { Fertility } \\
(\%)\end{array}$ & $\begin{array}{l}\text { Hatchability } \\
\text { of Fertiled } \\
\text { Eggs }(\%)\end{array}$ \\
\hline IKTA & 81.33 & 89.33 & 90.84 \\
White Texas & 60.00 & 84.00 & 71.72 \\
P-value & 0.028 & 0.51 & 0.023 \\
\hline
\end{tabular}

No significant differences were observed in fertility of the eggs, weight of the eggs, cleanliness of the eggs and shape index because less egg samples used than supposed to and the period of time during conducted this research was short. The samples used should be many and the period of this study should be long enough to determine the result. This statement was supported by Genchev (2012a) where the egg samples used must be plenty which until more than 400 quails be reared in one time to get the egg samples and the period of time for the study was around seven months. In addition, it also can be assumed that the fertility of the eggs between each strain was not significant due to the same ratio of male and female quail, same age of the quail and reared in the same environment at the quail farm.

Table 2: The parameter of hatchability rate between each strain

\begin{tabular}{lcccc}
\hline Breed & $\begin{array}{l}\text { Cleanliness } \\
(\%)\end{array}$ & $\begin{array}{l}\text { Smoothness } \\
\text { Texture of } \\
\text { Eggshell }(\%)\end{array}$ & Weight $(\mathrm{g})$ & $\begin{array}{l}\text { Shape Index } \\
(\%)\end{array}$ \\
\hline IKTA & 92.00 & 78.67 & $11.34 \pm 0.15$ & $78.57 \pm 0.69$ \\
White & 52.00 & 38.67 & $11.48 \pm 0.13$ & $79.14 \pm 0.53$ \\
Texas & 0.15 & 0.03 & 0.53 & 0.48 \\
P-value & & & & \\
\hline
\end{tabular}

Therefore, the correlation of the results for all the parameters in hatchability rate was obtained to determine the relationship of effect between all the parameters. All of the parameters could be related to each other in order to determine the hatchability rate in each strain. The cleanliness, smoothness texture of the eggshell, weight and shape index had a great effect to percentage of hatchability of incubated eggs, fertility of the eggs and hatchability of fertile egg. The shape index and weight could affect the percentage of hatchability and 
fertility of incubated eggs because it could determine the amount of albumen index inside the eggs that were important in embryo formation. It is supported by Akram et al. (2014) where the higher the egg weight from the normal weight of quail egg, the higher hatchability and fertility of quail eggs but for the shape index the higher the shape index from the normal shape index, the lower hatchability and fertility of quail eggs.

In addition, to relate between the shape index and weight of the eggs parameters with the hatchability of the incubated eggs, correlations must be found. From the correlation result obtained in Table 3, the Shape index and weight of the egg did not have relation with the percentage of the hatchability of incubated eggs. The correlation result was contrast from Akram et al. (2014). This is because it was not significant in shape index and weight of the egg between IKTA and White Texas strain.

Table 3: The correlation between hatchability of incubated eggs, shape index and weight of egg

\begin{tabular}{lll}
\hline Variables & Shape Index & Weight of Egg \\
\hline Hatchability Of Incubated & -0.339 & -0.106 \\
Eggs & & \\
\hline
\end{tabular}

On the same time, the cleanliness and smoothness texture of the eggshell also could give effect to the hatchability of the eggs especially for the number of hatchability of fertile eggs. Cleanliness of the eggs was observed to determine that it was free from dirt such as faeces from the quail hen and smoothness texture of eggshell was measured by touching and observed the shininess of the eggshell. The higher level of cleanliness and smoothness texture of eggshell contribute to the higher percentage for hatchability of fertile eggs. The exact cause of this finding was not known because of lack references to support for the reason.

Therefore, to relate between the cleanliness and smoothness texture of the eggshell parameters with the hatchability of the fertile eggs, correlations must be found. For the correlation result obtained in Table 4, the cleanliness and smoothness texture of the eggshell had relation with the percentage of the hatchability of fertile egg. This finding was showed from the results gained where IKTA strain that had higher level of cleanliness and smoothness of the eggshell than White Texas strain also had higher percentage hatchability of fertile eggs. Overall, the hatchability of incubated eggs, fertility of incubated eggs and hatchability of fertilized eggs for the IKTA strain was higher than the White Texas strain.

Table 4: The correlation between hatchability of fertiled eggs, cleanliness and smoothness texture of eggshell

\begin{tabular}{lll}
\hline Variables & Cleanliness & $\begin{array}{l}\text { Smoothness Texture } \\
\text { of Eggshell }\end{array}$ \\
\hline $\begin{array}{l}\text { Hatchability of Fertiled } \\
\text { Eggs }\end{array}$ & $0.713^{*}$ & $0.826^{*}$ \\
$*(\mathrm{P}<0.05)$ significant between group &
\end{tabular}

For egg quality, it was divided into two categories which were exterior trait of eggs and interior trait of eggs. In Table 5 showed the Parameters of the exterior trait of eggs between each strain. The parameters measured were shape index, egg weight, egg volume and eggshell surface. Table 6 showed the Parameters of the interior trait of eggs between each strain. The parameters measured were albumen index, Haugh unit and internal quality unit. All results for the exterior trait of eggs were not significant $(\mathrm{P}>0.05)$, however for interior trait of eggs the result for Haugh unit and internal quality unit was significant $(\mathrm{P}<0.05)$.

Table 5: The parameter of the exterior trait of eggs between each strain

\begin{tabular}{lcclc}
\hline Breed & $\begin{array}{l}\text { Shape } \\
\text { Index }(\%)\end{array}$ & $\begin{array}{l}\text { Egg } \\
\text { Weight }(\mathrm{g})\end{array}$ & $\begin{array}{l}\text { Egg } \\
\text { Volume } \\
\left(\mathrm{cm}^{3}\right)\end{array}$ & $\begin{array}{l}\text { Eggshell } \\
\text { Surface }\left(\mathrm{cm}^{2}\right)\end{array}$ \\
\hline IKTA & $78.15 \pm 0.63$ & $11.26 \pm 0.16$ & $10.70 \pm 0.21$ & $23.79 \pm 0.31$ \\
White & $78.48 \pm 0.15$ & $11.36 \pm 0.16$ & $10.81 \pm 0.09$ & $24.14 \pm 0.22$ \\
Texas & 0.57 & 0.65 & 0.65 & 0.31 \\
P-value & 0.57 &
\end{tabular}

Table 6: the parameter of the interior trait of eggs between each strain

\begin{tabular}{lccc}
\hline Breed & Albumen Index & Haugh Unit & Internal Quality Unit \\
\hline IKTA & $0.079 \pm 0.0024$ & $86.20 \pm 0.87$ & $54.06 \pm 1.33$ \\
White & $0.076 \pm 0.00053$ & $84.71 \pm 0.15$ & $51.14 \pm 0.50$ \\
Texas & & & \\
P-value & 0.067 & 0.022 & 0.048 \\
\hline
\end{tabular}

No significant differences were noted related to above; mentioned parameters because less egg samples used than supposed to and non-suitable and lack of equipment used to measure the egg quality parameters. This statement was supported by Zita, Ledvinka and Klesalova (2013) where the egg samples used must be plenty until more 2000 eggs used in one period time of the research and Genchev (2012b) stated that enough and suitable apparatus must be available and ready to be used in conducting and measure the egg quality.

However, even some of the results were not significant, the comparison between each strain in all parameters need to be study furthered. All of the parameters of exterior trait could affected the egg quality of interior trait in each strain. The egg quality actually was related to the hatchability rate of quail eggs. This statement was in agreement along with Hrncar, Hasunova, Hanus and Bujko (2014) who stated that rate of egg quality was important in effecting the hatching eggs.

For exterior trait of eggs results obtained, there were slightly different between IKTA and White Texas where it was slightly lower. The shape index and egg weight could give impact to the albumen index. This statement was supported by Zita, Ledvinka and Klesalova (2013) where heavier egg will produce less albumen index. On the other side, Genchev (2012b) stated that shape index could be referred to the age of quail during production of the eggs. During earlier production of quail eggs, the shape index is high. The egg volume depends on 
the shape index while eggshell surface depends on the weight of eggs.

For interior trait of eggs, the albumen index was nearly significant but the Haugh unit and internal quality unit were significant. The results on exterior trait of eggs could affect the results in interior trait of eggs. The IKTA strain achieved higher value of albumen index, Haugh unit and internal quality unit compare to White Texas strain because the eggs sample was lighter and less value in egg volume and eggshell surface. High value of weight and shape index could produce low albumen index while high amount of egg volume and eggshell surface could lower the value of the Haugh unit and internal quality unit of the eggs. This statement was supported by Genchev (2012b); Zita, Ledvinka and Klesalova (2013) and; Akram et al. (2014).

In addition, to relate between exterior trait of eggs parameters and interior trait of eggs parameters, correlations must be found. For the correlation results obtained in Table 7, the Shape index and weight of the egg did not have relation with the albumen index. The correlation result was contrast from Zita, Ledvinka and Klesalova (2013). This is because it was not significant in shape index and weight of the egg between IKTA and White Texas strain results. It also can be related with the hatchability rate, there was no relation between the shape index and weight of the eggs with the hatchability of the incubated eggs. Next, in Table 8, the Egg volume and eggshell surface had relation with Haugh units and internal quality units. This finding was showed from the results gained where IKTA strain who had less level of egg volume and eggshell surface than White Texas strain but higher in Haugh units and internal quality units as in agreement with Genchev (2012b); Zita, Ledvinka and Klesalova (2013) and; Akram et al. (2014). Overall, most of the results were significant because it can be related to the genetic information that inherited from the parents.

Table 7: the correlations between albumen index, shape index and weight of egg.

\begin{tabular}{lll}
\hline Variables & Shape Index & Weight of Egg \\
\hline Albumen Index & -0.041 & -0.13 \\
\hline
\end{tabular}

Table 8: the correlations between Haugh units, internal quality units, egg volume and eggshell surface

\begin{tabular}{lll}
\hline Variables & Egg Volume & Eggshell Surface \\
\hline Haugh Units & $-0.355^{*}$ & $-0.346^{*}$ \\
Internal Quality Units & $-0.586^{*}$ & $-0.590^{*}$ \\
\hline P $<0.05)$ significant between group &
\end{tabular}

\section{CONCLUSION}

The hatchability rate and egg quality between the IKTA and White Texas strains, there was a high significant different in hatchability of incubated and fertiled eggs, smoothness texture of the eggshell, and the Haugh unit but low significant different in internal quality unit of eggs. This showed that the IKTA strains was better than the White Texas strains. As to improve the quail eggs production in Malaysia, there should be more genetic study to be done in order to determine good strain and increase understanding about quail strain.

\section{ACKNOWLEDGEMENT}

Authors are thankful to the Faculty of AgroBased Industry, Universiti Malaysia Kelantan, Ruzlan Trading quail farm, Puyuh Jaya quail farm and Double Gold quail farm for giving space and cooperation to conduct this research.

\section{REFERENCES}

Akram, M., Hussain, J., Ahmad, S., Rehman, A., Lohani, F., Munir, A., Amjad, R., Noshahi, H. (2014). Comparative study on production performance, egg geometry, quality and hatching traits in four close-bred stocks of Japanese quail, $S$ journal Agricultural Advances, 3(1), 13-18.

Alkan, S., Karabag, K., Galic, A., Balcioglu, M.S. (2008). Effects of genotype and egg weight on hatchability traits and hatching weight in Japanese quail, South African Journal of Animal Science, 38 (3), 231-237.

Genchev, A. (2012a). Comparative investigation of the egg production in two Japanese quail breeds Pharaoh and Manchurian Golden, Trakia Journal of Sciences, 10 (1), 48-56.

Genchev, A. (2012b). Quality and composition of Japanese quail eggs (Coturnix japonica), Trakia Journal of Sciences, 10 (2), 91-101.

Hauber, M.E. (2014). The book of eggs: a life-size guide to the eggs of six hundred of the world's bird species, Chicago: The University Of Chicago Press, 14-17.

Hrncar, C., Hasunova, E., Hanus, A., Bujko. J. (2014). Effect of genotype in egg quality characteristics in Japanese quail (Coturnix Japonica), Slovak J. Animal Science, 47(1), 6-11.

Jatoi, A.S., Sahota, A.W., Akram, M., Javed. K., Jaspal, M.H., Mehmood, S., Hussain, J., Ishaq, H.M., Bughio. E. (2015). Egg quality characteristics as influenced by body size in four closebred flocks in Japanese quail (Coturnix coturnix japonica), the Journal Of Animal \& Plant Sciences, 25(4), 921-926.

Kumari, B.P., Gupta, B.P., Prakash, M.G., Reddy, A.R. (2008). A study on egg quality traits in Japanese quail, Tamilnadu J. Veterinary \& Animal Sciences, 4 (6), 227-231.

Lalev, M. (2013). A comparison of laying performance of egg type strains, Archiva Zootechnica, 16(2), 59-66.

Mizutani, M. (2003). The Japanese quail. Laboratory Animal Research Station, Nippon Institute for Biological Science, Kobuchizawa, Yamanashi, Japan, 408-0041, 143-163.

Moraes, T.G.V., Romao, J.M., Teixeira, R.S.C., Cardoso, W.M. (2008). Effects of egg position in artificial incubation of Japanese quail (Coturnix japonica), Animal Reprod., 5(1), 50-54.

Vali, N. (2008). The Japanese quail: a review. International Journal Of Poultry Science, 7(9), 925-931.

Zita, L., Ledvinka., Klesalova, L. (2013). The effect of the age of Japanese quails on certain egg quality traits and their relationship, Veterinarski Arhiv, 83 (2), 223- 232. 